\title{
La vuelta a la ingenuidad: un comentario sobre el realismo natural de Hilary Putnam
}

Eduardo M. González de Luna Universidad Autónoma de Querétaro

Abstract

Hilary Putnam has acquired a reputation for frequently changing his philosophical position. In relation to the problem of realism, he originally defended a position called metaphysical realism, but eventually became one of its critics, first adopting a view he called "internal realism", which he later abandoned in favor of a direct realism. Putnam's direct realism aims to return the study of reality to the way ordinary people actually experience the world, rejecting the idea of mental representations, sense data, or other intermediaries between mind and world. The aim of this paper is to present a view of this alternative direct realism that he calls "natural realism" and comment on his relation with other types of direct realism, in particular the realism of Thomas Reid.

Keywords: perception, representation, direct realism, natural realism.

\section{Resumen}

Hilary Putnam ha adquirido la reputación de cambiar frecuentemente sus posturas filosóficas. En relación con el problema del realismo, originalmente defendió una postura llamada realismo metafísico, pero eventualmente se volvió uno de sus críticos, adoptando primeramente una concepción llamada "realismo interno" que luego abandonó a favor del realismo directo. 
El realismo directo de Putnam intenta regresar el estudio de la realidad a la manera como la gente ordinaria experimenta el mundo, rechazando la idea de representaciones mentales, sense data u otros intermediarios entre la mente y el mundo. El propósito de este artículo es presentar una apreciación de este realismo directo alternativo, que llama "realismo natural", y hacer un comentario sobre su relación con otras formas de realismo directo, en particular con el realismo de Thomas Reid.

Palabras clave: percepción, representación, realismo directo, realismo natural.

\section{Introducción}

U Tna de las cuestiones que durante siglos ha ocupado a los filósofos ha sido la referente a la relación entre mente, cuerpo y mundo o, en otros términos, entre nuestras percepciones y la realidad. Las reflexiones de Hilary Putnam sobre los fundamentos de las ciencias cognitivas le han llevado a romper con algunos supuestos adoptados sin cuestionamiento en la tradición epistemológica; los cuales, a su juicio, han conducido al planteamiento de pseudo-problemas y falsas dicotomías como las que se aprecian en los debates contemporáneos entre el realismo y el antirrealismo. Con este rompimiento Putnam busca revalorar el papel de la percepción en la búsqueda de respuestas al problema de "lo que hay" en el mundo, recuperando parte de la tradición pragmatista y reevaluando el papel de la acción en la constitución y conceptualización del conocimiento. El recorrido de Putnam, que inicia con la revisión de los presupuestos que subyacen en los debates clásicos del realismo, le lleva a la negación de tales supuestos y a una recuperación de planteamientos hasta hoy considerados marginales, dando como resultado sorprendente un nuevo regreso hacia al realismo ingenuo del hombre común. 


\section{El realismo externo}

Una de las características de Putnam ha sido la constante reconsideración de sus propios puntos de vista. En una primera etapa de su filosofía, defendía un realismo metafísico o externo, a saber, la concepción de que las categorías y las estructuras del mundo externo son tanto causal como ontológicamente independientes de las conceptualizaciones de la mente humana. Desde una teoría externalista del significado, criticaba el verificacionismo y el relativismo, adoptando una defensa del realismo científico. En esta época propone también el funcionalismo en filosofía de la mente. En sus primeras formulaciones del funcionalismo planteaba que la mente era básicamente como una computadora y que lo pertinente para el estudio de las cuestiones cognitivas era sólo su organización; desde esta perspectiva, para explicar el conocimiento no es necesario presuponer una mente, ni siquiera un cerebro, ya que el mismo estado cognitivo podría producirse con diferentes bases materiales.

A fines de los setenta su pensamiento cambió con su crítica al realismo metafísico y al materialismo reduccionista que culminó con su propuesta del realismo interno. Según Putnam, el realismo metafísico o externo supone una brecha entre la forma como el hombre concibe al mundo y la forma como el mundo es en realidad. Esta visión ha conducido al planteamiento de paradojas escépticas, tales como la del "genio maligno" cartesiano, o en términos contemporáneos, al problema de los "cerebros en cubetas". Este último consiste en la imposibilidad de responder a la pregunta de si somos o no cerebros en cubetas conectados a una computadora, la cual transmite en nosotros la información con la cual construimos nuestra realidad. Putnam muestra que esta pregunta supone, para ser inteligible, una concepción metafísica del mundo real que lo concibe como separado de nuestras capacidades cognitivas. El problema de los cerebros en cubetas sólo puede plantearse desde esta concepción, aunque su 
respuesta sólo podría darse desde una perspectiva externa, como la del "ojo de Dios", y no desde una perspectiva humana, pues estamos limitados por nuestros esquemas conceptuales. Entonces, el problema de los cerebros en cubetas es ab initio irresoluble para el humano y en consecuencia ininteligible; depende de la adopción del realismo metafísico y conduce irremediablemente al escepticismo: se trata de un pseudo-problema filosófico.

\section{El realismo interno}

Como alternativa al realismo metafísico o externo, Putnam propone al realismo interno, que afirma que toda realidad estructurada y la experiencia que tenemos de ella están determinadas por los marcos conceptuales de los sujetos que la conocen y que interactúan con ella. El realismo interno busca dar una respuesta diferente a las del externalismo y el escepticismo respecto al problema del conocimiento del mundo real.

Partiendo de un punto de vista kantiano, el internalismo pretende recuperar la noción de sentido común sobre la realidad del mundo que nos rodea. El realismo interno se opone así a la perspectiva del realismo metafísico que resulta incompatible con la visión de la realidad del hombre ordinario, pues, como ya he mencionado, una opinión de los filósofos externalistas es afirmar, como lo hace también el escéptico, que los objetos del sentido común no existen realmente tal y como los percibimos ya que no podemos apreciar directamente las propiedades reales de estos objetos (o al menos no todas) sino sólo proyecciones de ellas. En la postura externalista encontramos pues un escepticismo con respecto a la visión del mundo del sentido común que el internalista busca recuperar.

Según Putnam, sólo tiene sentido formular la pregunta ¿de qué objetos consta el mundo? desde dentro de una teoría o descripción, es decir, desde una perspectiva interna que está determinada por los 
marcos conceptuales mediante los cuales representamos al mundo. La propuesta del realismo interno consiste entonces en aceptar el supuesto del realismo metafísico sobre la realidad del mundo que nos rodea; pero negar la pretensión de que hay un mundo real con una estructura última dada, es decir, con una estructura formada por entidades como objetos, hechos y relaciones que sea independiente de nuestras posibilidades de experiencia y conocimiento. De acuerdo con esto, es válido en principio creer que el mundo en que vivimos, constituido por las entidades con las que nos relacionamos, es real, de acuerdo al sentido común de la vida diaria, pero no es válido sostener la creencia de que existe un mundo de objetos en sí, de objetos que se auto-identifiquen o que el mundo o alguna instancia superior a nosotros (Dios) identifique con independencia de los conceptos que dan referencia a esos objetos. En esta postura, el realismo va unido a un pluralismo al nivel de los conceptos: lo real es siempre relativo al marco conceptual que se usa para representar al mundo real.

En una tercera etapa, Putnam abandona la idea del realismo interno. Sigue cuestionando el realismo metafísico, pero cuestiona también toda perspectiva filosófica que atente contra el sano sentido común ya que hay una manera errónea de interpretar el realismo interno, a saber, como una perspectiva idealista que afirme la dependencia de la realidad del sujeto, sea individual o social. Una postura filosófica como ésta, violaría la naturalidad del sentido común tanto o más que la apelación a un mundo oculto de cosas en sí mismas, como postula el realismo metafísico.

\section{Distintas formas del realismo perceptivo}

Entonces, desde mediados de los noventa del siglo XX, el realismo interno es revisado y reformado para transformarse en un realismo natural — término acuñado por William James - que es un realismo que adopta tesis de los pragmatistas clásicos, para proponer un 
realismo de sentido común, en el que tenemos acceso directo a la realidad mediante la percepción (entonces es también un realismo perceptivo). El realismo natural así concebido coincidiría con lo que se ha llamado, "el realismo ingenuo del hombre común", y Putnam reivindica un retorno a tal realismo, a lo que llama "la segunda ingenuidad". Es decir, debemos retornar como filósofos a las intuiciones del realismo ingenuo que hemos perdido; pero este retorno estará ahora justificado por argumentos filosóficos.

Para caracterizar mejor al realismo directo de Putnam, conviene revisar algunos conceptos concernientes al realismo perceptivo.

\section{El realismo perceptivo directo e indirecto}

El llamado realismo ingenuo tradicionalmente ha sido un realismo directo con respecto a la percepción, o un realismo perceptivo directo. El realismo directo sostiene que en la percepción sensorial captamos directamente la existencia y la naturaleza del mundo físico. Los objetos de la percepción son objetos directos, en el sentido de que se captan directamente sin intermediarios. ${ }^{1}$

El realismo en teoría de la percepción, o realismo perceptivo, se caracteriza por la tesis "de que los objetos que percibimos tienen la posibilidad de existir, y normalmente existen, conservando algunas de las propiedades que percibimos que tienen, incluso cuando no son percibidos" (Dancy, 1993: 168).

Dentro del realismo perceptivo, la diferencia entre el realismo directo y el realismo indirecto reside en la forma de la percepción, ya sea con o sin intermediarios. La percepción de un objeto $O$ por parte de un perceptor $P$ es directa, si $P$ percibe a $O$ sin percibir ningún

${ }^{1}$ Este es el sentido de directo que nos interesa discutir aquí, pues es el que adopta Putnam. Pero más adelante mencionaré que en la filosofía se ha defendido otro sentido de directo como "no inferencial", a la manera de Thomas Reid y otros. 
intermediario $I$. Se dice que $P$ percibe un intermediario $I$, si $P$ percibe a $O$ sólo en virtud de que percibe a $I$. La percepción indirecta es entonces aquella en la cual $P$ percibe a $O$ vía un intermediario $I$. En la percepción indirecta se requiere que el modo en que $P$ aprehende a $I$ sea análogo al modo en que aprehende a $O$.

Tanto el realista directo como el indirecto coinciden en que los objetos físicos pueden existir y mantener algunas de sus propiedades con independencia de cualquier perceptor. La discrepancia entre ellos consiste en que para el realista indirecto, la aprehensión de los objetos físicos nunca es directa, pues sólo se captan indirectamente en virtud $d^{2}{ }^{2}$ la captación directa de un objeto intermedio (no físico) que puede llamarse indistintamente una idea, dato sensorial, qualia, apariencia, representación, etc. Putnam llama la visión interfaz de la mente a esta tesis del realismo indirecto y la atribuye a los filósofos clásicos de la tradición cartesiana, sean racionalistas o empiristas.

La dificultad que señala Putnam consiste en introducir un papel para las representaciones mentales en general, ya que éstas podrían concebirse como una interfaz entre nosotros y esto sería inconsistente con el realismo directo. Sin embargo, creo que es posible defender un modelo consistente que acepte la existencia de representaciones en el marco de un realismo directo. Esto lo indicaré más adelante, cuando exponga la teoría de la percepción de Thomas Reid.

${ }^{2}$ Frank Jackson (1993: 19-20) usa la expresión en virtud de para definir la distinción entre objetos mediatos (indirectos) e inmediatos (directos) de la percepción. Comúnmente vemos cosas en virtud de ver otras cosas. Por ejemplo, ver una mesa en virtud de ver su parte superior. Según la definición de Jackson: " $x$ es un objeto mediato de percepción (visual) (para $S$ en $t$ ) si y sólo si $S$ ve $x$ en $t$, y hay una $y$ tal que $(x \neq y$ y) $S$ ve $x$ en virtud de ver $y$. Un objeto inmediato de percepción es uno que no es mediato; y podemos definir la relación de percibir inmediatamente así: $S$ percibe inmediatamente $x$ en $t$ si y sólo si $x$ es un objeto inmediato de percepción para $S$ en $t^{\prime \prime}$.

Según esta definición, en el ejemplo anterior, $S$ ve la mesa mediatamente y ve su parte superior inmediatamente. (Todas las traducciones de Jackson son mías). 
Hay una forma alternativa de concebir al realismo directo (o inmediato), Jackson discute esta forma, que identifica el término "directo" con "no inferencial" (Jackson, 1993: 6-9). ${ }^{3}$ Es una consecuencia de la doctrina que afirma que la distinción entre percepción mediata e inmediata es que la última, pero no la primera, es no inferencial. Según esta concepción, la percepción directa consiste en percibir sin necesidad de hacer inferencias o de tener creencias previas que determinen la percepción. Para Jackson esta identificación falla precisamente porque la inferencia es una noción definible en términos de creencia; inferir es al menos creer algo como resultado de creer otra cosa. Así que: "decir que la percepción mediata, por contraposición con la percepción inmediata, involucra inferencias es decir que la percepción mediata involucra ciertas creencias que la percepción inmediata no involucra; y esto es falso" (Jackson, 1993: 8). Pero éste es un tema muy controversial y no podemos tratarlo aquí.

\section{El realismo perceptivo directo: ingenuo y científico}

Como hemos mencionado, el realismo directo sostiene que en la percepción sensorial captamos directamente la existencia y la naturaleza del mundo físico. Los objetos de la percepción son entonces los objetos reales.

Todos los realistas directos coinciden en que los objetos físicos percibidos pueden existir y conservar al menos algunas de las propiedades que les atribuimos al percibirlos, aun cuando no los percibamos. Sin embargo, discrepan sobre cuáles son las propiedades que los objetos físicos mantienen, es decir, sobre el grado de realismo

\footnotetext{
${ }^{3}$ Más adelante veremos que Thomas Reid defiende un realismo directo de tipo no inferencial, al que Putnam se opone por considerarlo un representacionismo disfrazado.
} 
que aceptan. De acuerdo con esto, es posible distinguir entre dos tipos principales de realismo perceptivo directo, a saber, el ingenuo y el científico (Dancy, 1993: 171).

El realista directo ingenuo sostiene que "los objetos no percibidos pueden retener propiedades de todos los tipos que percibimos que tienen" (Dancy, 1993: 172). Según Dancy, la ingenuidad de esta postura radica en la palabra "todos", y es posible matizarla sustituyéndola por "la mayoría". Lo cual conduce al realismo directo científico.

El realismo directo científico recibe este nombre porque parte de la perspectiva científica que ha demostrado que los objetos físicos no retienen, cuando no los percibimos, todas las propiedades que les atribuimos cuando los percibimos. Para esta postura, la existencia de algunas de esas propiedades depende de un perceptor. Por ejemplo, el color, el sabor o la aspereza no son propiedades inherentes al objeto que se mantengan con independencia de un perceptor. El objeto sólo las posee en relación con un perceptor. El realismo directo científico acepta que la percepción del mundo es directa, pero restringe este carácter directo sólo a algunas de las propiedades del objeto.

Esta distinción del realismo directo científico nos recuerda la distinción de Locke sobre las cualidades primarias y secundarias de un objeto. Según Locke, las cualidades primarias de un objeto, como la forma o el tamaño, tienen diferente estatuto ontológico que el de las cualidades secundarias como el color, el sabor o el olor. El objeto retiene las cualidades primarias, pero pierde las secundarias cuando no es percibido. En cierto sentido podría decirse que las cualidades secundarias de un objeto son un efecto de sus cualidades primarias; pues, gracias a que el objeto retiene sus cualidades primarias, las secundarias aparecerán a cualquier perceptor en las circunstancias apropiadas. Una cualidad secundaria es más una propiedad de la manera en que el perceptor aprehende el mundo, que una propiedad del mundo mismo. 
Según Dancy, pueden hacerse dos observaciones en contra de la forma científica de realismo directo. La primera se basa en la dificultad para distinguir, en nuestra experiencia del mundo, las cualidades primarias y secundarias. Ambas propiedades nos aparecen entremezcladas en la experiencia y con un estatuto semejante. Y un mundo de puras cualidades primarias sería imposible de imaginar, pues parecería imposible percibir los objetos de ese mundo sin percibir sus cualidades secundarias. La segunda observación es sobre una posible incompatibilidad entre la visión realista directa y la distinción de cualidades primarias y secundarias. Para el realista directo, la aprehensión de cualidades secundarias, como el color o el olor, es tan directa en la experiencia como lo es la aprehensión de cualidades primarias, como el tamańo y la forma. La dificultad se basa en que si se concede la existencia de alguna cualidad secundaria de un objeto, por ejemplo el color, esto implicaría que ésta no es una propiedad del objeto mismo, por tanto habría que descubrir algún otro tipo de objeto intermediario que sí fuera portador de la propiedad secundaria, es decir, que sí fuera coloreado, pero este argumento conduciría al realismo indirecto del cual hablamos en la anterior sección.

La forma ingenua de realismo directo parece ser más consistente que la forma científica. Dancy considera y responde a algunas objeciones para el realismo directo ingenuo que, en su mayoría, son aplicables también al realismo directo científico.

El primer problema se basa en la resistencia a aceptar el color-talcomo-lo-vemos como algo que existe cuando nadie lo percibe. Según este argumento (Dancy, 1993: 175), el color percibido se altera de acuerdo con el estado no sólo del objeto, sino también del perceptor y de la luz del medio ambiente. Por tanto, no puede haber tal cosa como el color real del objeto, pues cualquier elección de los muchos colores percibidos como color real será arbitraria y dependería del criterio de los seres humanos. Pero, si se acepta que el color real depende del criterio humano, esto parece llevar a un abandono de la noción de 
que los objetos conservan un color cuando nadie los percibe. Dancy responde que no es necesario que el color real sea el que se mantiene cuando nadie percibe al objeto. El objeto puede mantener un color no percibido que bien puede no ser su color real. Dancy sugiere que, en el realismo ingenuo, el color real puede definirse como el color que se percibe bajo condiciones normales. Con esto, el objeto podría conservar un color no percibido, que puede no ser su color real, sin por esto tener que comprometerse en decir cuál es ese color no percibido. Para Dancy, la sugerencia de que algún color se mantiene no percibido es una buena respuesta a la objeción mencionada, pues es compatible con el punto de vista de que percibimos objetos físicos directamente como coloreados y con el punto de vista del color de un objeto puede alterarse de acuerdo con el medio circundante.

De aquí surge otra objeción para el realismo ingenuo que se basa en el hecho de que los objetos pierden su color en la oscuridad. Esto puede ser indicador de que el color sólo existe en condiciones apropiadas para la percepción, y dificultar así la posible existencia del color no percibido. Pero según Dancy, el realista ingenuo no necesita aceptar que los objetos pierden su color en la oscuridad (Dancy, 1993: 169), sino que puede decir que los objetos mantienen un color que, debido a las condiciones desfavorables, no se puede ver. Aun si se concede que el color desaparece en la oscuridad puede darse una respuesta más: el realista ingenuo puede decir que el hecho de que el color no exista en ausencia de la luz adecuada no muestra que el color no pueda existir sin ser percibido, siempre que se admita que la luz adecuada puede estar presente sin ser percibida.

2. El realismo perceptivo indirecto: ingenuo y científico

Como ya se ha mencionado, el realismo indirecto mantiene que en la percepción aprehendemos indirectamente los objetos externos que 
nos rodean en virtud de la aprehensión directa de objetos internos, como ideas, datos de los sentidos, representaciones, etc. Como en el caso del realismo directo, hay una forma ingenua y una forma científica de realismo indirecto.

El realismo indirecto ingenuo afirma que el objeto interno de aprehensión tiene propiedades de los mismos tipos que las propiedades del objeto externo. De modo que el objeto indirecto externo tiene tanto color, olor, sabor, etc., como forma y tamaño. El realismo indirecto científico sostiene que el objeto externo sólo tiene propiedades primarias, como forma y tamańo, y que las propiedades secundarias (las sensoriales como el color) sólo pertenecen al objeto directo, que en su caso es interno.

Según Dancy, la forma ingenua del realismo indirecto es insostenible. Pues implica la sugerencia de que aparte de los colores visibles del objeto interno directo hay otros colores invisibles que pertenecen al objeto externo indirecto. Pero "sentimos la fuerte tentación de decir que el color es algo que sólo podemos aprehender directamente, al menos en los casos normales" (Dancy, 1993: 180). Pero la forma científica del realismo indirecto es más plausible. Entraña la separación entre propiedades primarias y secundarias que parece compatible con la visión científica del mundo.

\section{Algunos antecedentes históricos del realismo perceptivo}

En la antigua Grecia se conocían dos concepciones opuestas sobre la percepción. La teoría de la percepción aristotélica era una forma de lo que ahora llamamos realismo directo que rivalizaba con la teoría de la percepción de los atomistas y los estoicos que era de tipo representacional y un antecedente del actual realismo indirecto. 


\section{El realismo aristotélico}

Según Putnam, la concepción de Aristóteles tiene fuertes elementos de realismo directo en el sentido siguiente: ${ }^{4}$ en el libro III de De Ani$m a$, se dice que "La parte pensante del alma, permaneciendo impasible, debe ser capaz de recibir la forma de un objeto, esto es, debe ser potencialmente lo mismo que su objeto sin ser el objeto" (Aristóteles, 1999: 429a).

Para Aristóteles, la forma de un perceptible puede ser una propiedad perceptible. Por ejemplo, la forma de una esfera de bronce puede ser su figura, con independencia de la materia en la que esta forma se realiza; también la forma de un animal humano puede ser su animalidad racional. La teoría aristotélica nos desconcierta porque no es comprensible en términos actuales en qué sentido la mente puede llegar a ser potencialmente esférica, o caliente, cuando se percibe algo caliente. Pero la doctrina aristotélica es clara en lo que respecta a que lo que percibimos es la calidez, la figura, o la inteligencia y la animalidad de la persona con la que hablamos. En la interpretación de Putnam, la idea compartida por escépticos y realistas indirectos de que lo que percibimos sólo es un acontecimiento que se da en una interfaz dentro de nosotros mismos y que es causado por la propiedad del objeto de la percepción es extraña a Aristóteles y producto de la epistemología moderna (Putnam y Nussbaum, 1997: 75).

\section{El realismo directo de Thomas Reid}

Durante el periodo moderno el realismo directo prácticamente desapareció del debate filosófico, salvo por la postura sostenida por la llamada escuela escocesa del sentido común en el siglo XVIII, que surgió

\footnotetext{
${ }^{4} \mathrm{Al}$ menos esto se puede derivar de la interpretación escolástica, según Putnam y Nussbaum en Modificando la (concepción de la) mente de Aristóteles (Putnam, 1997: 74).
} 
como reacción en contra de las tesis escépticas de los racionalistas y los empiristas. Thomas Reid, considerado su fundador y principal exponente, sostuvo un realismo directo en el cual, mediante la percepción, podemos captar las cualidades de los objetos externos tal y como son.

Un principio reidiano del sentido común afirma que las cosas que distinguimos claramente mediante los sentidos "realmente existen, y son lo que percibimos que son". Esta concepción de la percepción conlleva un compromiso con el realismo directo contraria a la concepción representacionista de la tradición filosófica imperante, que supone un realismo indirecto. Para Reid, todos los filósofos del representacionismo, de Platón a Hume, coincidían en que no percibimos los objetos externos de manera inmediata, y que el objeto inmediato de la percepción debe ser algún objeto presente a la mente, es decir, una idea o una impresión. Este planteamiento equivocado es lo que ha llevado al escepticismo y otros problemas irresolubles.

Según Reid, lo que lleva a un escepticismo con respecto a los objetos externos es la reificación que los filósofos hacen de los contenidos del pensamiento, considerándolos además como los únicos objetos presentes directamente a la conciencia: "Siendo [en los sistemas escépticos] las ideas los únicos objetos del pensamiento y no teniendo existencia alguna, salvo cuando somos conscientes de ellas, de ahí se sigue necesariamente que no hay ningún objeto de nuestro pensamiento capaz de tener una existencia continua y permanente" (Reid, 1764: 113).5

En la opinión de Reid, la reificación que hacen los filósofos sobre los contenidos mentales a costa de la negación del mundo material no está necesariamente justificada, pues tanto o más válido sería el partir de la reificación de sí mismo o de los objetos externos, como lo pide el sentido común.

${ }^{5}$ Las traducciones de Reid son mías. 
Es importante notar que más que una negación de la existencia de las ideas en general, Reid argumenta que, en lo concerniente a nuestra percepción de los objetos externos, son estos los objetos inmediatos de la percepción y no las ideas o representaciones que tenemos de ellos. Este es un punto clave para entender el tipo de realismo directo que propone.

En su teoría de la percepción, Reid parte de la negación de las premisas de las teorías racionalistas y empiristas que ya hemos expuesto, las cuales afirman que cuando percibimos, lo hacemos por medio de ideas situadas entre la mente y los objetos materiales percibidos, por el contrario, dice: "El término percepción se asigna del modo más apropiado a la evidencia que tenemos de objetos externos a través de nuestros sentidos" (Reid, 1785: 8).

Reid cuestiona también que el conocimiento de los objetos externos se alcance por medio del razonamiento, es decir, argumenta a favor del conocimiento directo de los objetos; y también cuestiona que para llegar a concebir algo sea necesario tener una impresión o idea previa en nuestras mentes que se le asemeje. Dice: "Cuando oigo un cierto sonido, concluyo inmediatamente, sin razonamiento, que un carruaje pasa. No hay premisas desde las cuales esta conclusión se infiera mediante algunas reglas de la lógica. Es el efecto de un principio de nuestra naturaleza, común a nosotros y a los brutos" (Reid, 1764: 29). ${ }^{6}$

La conclusión de la que habla Reid, no es una conclusión a la que se llegue mediante un razonamiento, sino una creencia a la que se llega mediante un proceso causal, directo y no inferencial: las sensaciones son signos de los objetos externos, y es así como las debemos considerar siempre, de acuerdo a los dictados del sentido común: "Las sensaciones de olor, sabor, sonido y color, son infinitamente más importantes como signos o indicaciones que lo que son por propia

\footnotetext{
${ }^{6}$ Es de notar la opinión de Reid acerca de la existencia de una naturaleza perceptiva común a los animales y los humanos.
} 
cuenta; como las palabras de un lenguaje, en donde no atendemos al sonido sino al sentido" (Reid, 1764: 25). ${ }^{7}$

Esta analogía aclara el papel de las sensaciones en el proceso de la percepción. Como los sonidos de las palabras de un lenguaje hablado, no percibimos a las sensaciones como signos, sino directamente a los objetos externos. ${ }^{8}$

Esta concepción hace del realismo de Reid un realismo directo en el sentido de no inferencial, aunque en la interpretación de Putnam Reid mantiene una concepción interfaz respecto a las sensaciones. $\mathrm{Si}$ Putnam tiene razón en su interpretación, el realismo de Reid sería sólo declarativamente un realismo directo, pues en realidad sería un tipo de realismo indirecto, ya que propondría a las sensaciones como intermediarios mentales. Sin embargo, Reid insiste en no reificar las sensaciones a costa de negar el objeto externo. Pues al percibir un objeto lo que percibo no son las sensaciones. En mi opinión esto muestra que, según Reid, el aceptar la posible existencia de sensaciones por sí sólo no compromete con el realismo indirecto. Todo depende del papel que se asigne a las sensaciones en el proceso perceptivo. Si bien el realismo directo de Reid no es estrictamente de tipo aristotélico ya que puede admitir la posible existencia de sensaciones en el proceso de la percepción, sí podemos considerarlo por el momento un realismo directo en el sentido de no inferencial.

Desde mi punto de vista, Reid no mantiene una concepción interfaz de la percepción como supone Putnam, pues sus argumentos en contra de la teoría cartesiana de las ideas son muy parecidos a los de Putnam a favor del realismo natural y en contra de la interfaz.

\footnotetext{
${ }^{7}$ Reid aplica el término sensación a objetos de la experiencia introspectiva.

${ }^{8}$ De la misma manera se puede defender un realismo directo desde una teoría representacionista de la mente. Se puede argumentar que aunque en la percepción estén involucradas representaciones, el objeto de la percepción es el objeto externo, y no la representación o algún tipo de sense data.
} 
Como hemos visto ya, Reid hace un reclamo a los filósofos que mantienen teorías de la percepción que interponen a las ideas entre la mente perceptora y el objeto externo, a aquellos que reifican innecesariamente imágenes en la mente o el cerebro, que dan tal objetividad al mundo del pensamiento que llegan a confundirlo con los objetos percibidos. Para Reid estos filósofos conciben a las ideas como una clase de entidades que a veces se ligan con el pensamiento, a veces son el objeto del pensamiento, y a veces tienen una existencia propia. ${ }^{9}$ Reid afirma que no hay ninguna prueba concluyente de la existencia de las ideas (en el proceso de la percepción); y que éstas, concebidas como intermediarios entre la mente y los objetos externos, son meras ficciones o hipótesis propuestas con el fin de resolver el fenómeno del entendimiento humano. Sin embargo, lejos de cumplir con esta meta, suponer ideas o imágenes de cosas en la mente como intermediarios sólo ha llevado a paradojas inaceptables. ${ }^{10}$

El argumento de Reid se refiere específicamente aquí al proceso de la percepción de los objetos externos mediante los sentidos. Según los dictados del sentido común, percibimos directamente a los objetos materiales, no a las ideas como representaciones de estos. Es importante notar que el argumento de Reid no busca tanto negar la existencia de los contenidos mentales, sino que su crítica se dirige a la pretensión de reificar estos contenidos a costa de negar la existencia de los objetos externos, es decir, objeta la tesis de que los objetos mentales son una interfaz entre nosotros y el mundo, aunque pueda aceptar su existencia como parte del proceso perceptivo. Esto hace que el realismo directo de Reid sea insatisfactorio para Putnam, ya

\footnotetext{
${ }^{9}$ Reid aplica el término idea a todo tipo de contenido mental.

${ }^{10}$ Como veremos a continuación, Putnam llama "concepción interfaz" a la opinión de que en la percepción captamos directamente objetos intermedios como ideas, sense data, representaciones, etc., y no tocamos directamente al mundo, sino sólo indirectamente en el mejor de los casos.
} 
que a pesar de todo concede un papel a las ideas (y a las sensaciones) en el proceso de la percepción.

Por otra parte, Reid, al igual que Descartes y Locke, distingue entre cualidades primarias y secundarias de los objetos, y también sostiene, aunque en un sentido diferente, que sólo las cualidades primarias nos informan de lo que estas cualidades son en sí mismas:

La noción que tenemos de las cualidades primarias es directa, y no solamente relativa. Una noción relativa de una cosa [como la de las cualidades secundarias] no es, hablando estrictamente, una noción de la cosa, sino sólo de alguna relación la cual señala a algo más (Reid, 1785: 105).

A primera vista, parece haber una inconsistencia entre la distinción de cualidades primarias y secundarias de los objetos externos y el realismo directo. Pero agrega:

No es de esperar que estos [el vulgo] deberían hacer distinciones que no tengan conexión con los asuntos comunes de la vida; ellos no [...] distinguen las cualidades primarias de las secundarias, sino que hablan igualmente de ambas como cualidades del objeto externo [...] De las secundarias, sus nociones son [...] confusas e imprecisas, más que erróneas (Reid, 1785: 107).

Ambos puntos de vista pueden reconciliarse para evitar el escepticismo, aceptando el punto de vista del hombre común sobre las cualidades secundarias: el color de un objeto, que es una cualidad secundaria del mismo, sí es una cualidad, aunque oscura e imprecisa, del objeto externo; es aquella cualidad que nos produce la sensación del color que vemos. Como hombres comunes, podemos con corrección decir que un objeto que vemos rojo, es rojo, puesto que llamamos "rojez" a la cualidad secundaria correspondiente del objeto.

Reid resume su teoría de la percepción en los siguientes términos:

Si atendemos al acto de nuestra mente que llamamos percepción de un objeto sensible externo, encontraremos en él estos elementos: primero, una 
concepción o noción del objeto percibido; segundo, una fuerte e irresistible convicción o creencia en su existencia presente; y, tercero, el que esta convicción o creencia es inmediata, y no el efecto de un razonamiento (Reid, 1785: 50).

Es importante notar aquí el compromiso realista que para Reid conlleva la percepción de un objeto del mundo externo: Percibir un objeto externo es aceptar su existencia.

\section{El realismo directo contemporáneo}

Según Putnam, el realismo directo volvió a surgir en el siglo XX con las críticas de William James a la concepción tradicional sobre la percepción, es decir, a la concepción representacional. Posteriormente John Austin desarrolló una defensa del realismo natural o de sentido común, en el seno de la filosofía analítica. En la interpretación de Putnam, la filosofía del segundo Wittgenstein constituye también una defensa de esta forma particular del realismo.

La diferencia con la concepción cartesiana clásica reside en que en ella se asume que los objetos de la percepción inmediata eran mentales y por lo tanto no físicos, interponiendo de esta manera, como argumenta también McDowell, interfaces entre nuestros poderes cognitivos y el mundo exterior. Putnam rechaza la concepción tradicional de que las experiencias sensoriales son experiencias intermediarias entre nosotros y el mundo. Pero la alternativa de Putnam no implica negar la conciencia fenoménica y la experiencia subjetiva, sino afirmar que las cosas externas pueden ser experimentadas, y no sólo en el sentido trivial de ser meras causas de experiencias entendidas éstas como afecciones de la subjetividad, sino directamente tal y como ellas son. Entonces, para completar el itinerario del viaje de retorno que va del realismo ingenuo al realismo natural, es necesario cuestionar la imagen tradicional en su conjunto, es decir, la concep- 
ción interfaz. Este largo itinerario se hace necesario si se quiere adoptar una alternativa filosófica que nos permita mantener las intuiciones realistas pero sin caer en las dos concepciones falsas sobre el problema de la realidad, a saber, el realismo metafísico y el antirrealismo, las cuales tienen como denominador común a la concepción interfaz. Pero la crítica a esta concepción se extiende hasta el realismo interno, siempre que se considere una interfaz a los marcos conceptuales que determinan los objetos del mundo.

\section{El realismo natural de Putnam}

Usando las distinciones ya expuestas podemos caracterizar el realismo natural de Putnam con respecto a la percepción como un realismo directo, entendiendo directo como sin interfaces mentales y no en el sentido de no inferencial. Putnam denuncia como falsa la clásica visión interfaz de la mente que interpone entidades como los qualia entre el sujeto y el mundo. Es decir, al igual que Reid, ataca al realismo indirecto por reificar las entidades mentales a costa de cuestionar los objetos externos. Niega a su vez que sea un problema filosófico auténtico el de la forma como se conectan la mente y el mundo, algo que preocupó tradicionalmente a la epistemología. La respuesta del realista natural a esa cuestión es la siguiente: la mente y el mundo se conectan porque nuestras capacidades perceptivas y cognitivas nos permiten captar directamente el mundo tal como es, sin ningún intermediario.

La percepción exitosa consiste precisamente en ver o escuchar las cosas que están "allí afuera", y una falla en la percepción supone que la cosa captada no está allí en realidad. Si atendemos al uso común de los términos, la percepción exitosa consiste en la captación directa de las cosas del mundo y no en una mera afección de la subjetividad de la persona causada por esas cosas.

Al identificar al realismo natural con el realismo ingenuo del hombre común, Putnam se opone tanto a los argumentos escépticos 
del racionalismo y el empirismo clásicos, como al realismo científico tradicional en su defensa a ultranza de una visión científica del mundo, pues todas estas corrientes cuestionaron la concepción de sentido común acerca del mundo por suponerla falsa. Putnam ubica las raíces de la visión interfaz en Platón, y posteriormente en la época moderna en la teoría cartesiana de la mente, y sugiere que una solución al viejo problema del realismo que represente un verdadero progreso en filosofía requiere de una vuelta al realismo directo aristotélico pero eliminando sus aspectos metafísicos. En este camino es necesario recuperar la importancia de la percepción para el problema del realismo.

\section{La concepción interfaz de la experiencia}

Según Putnam, la concepción interfaz de la percepción ha llevado tanto al escepticismo como al planteamiento de la dicotomía realismo metafísico-antirrealismo como una vía para escapar de ella. Un argumento para fundamentar esto es el siguiente: Descartes en la Primera Meditación argumentó que la experiencia al soñar es idéntica de la experiencia de vigilia y, por consiguiente, que no tenemos garantía de que lo que percibimos en nuestra experiencia actual sea verdadero. Pues si una experiencia verídica puede ser idéntica a una experiencia no verídica, entonces no tenemos garantía ni siquiera de que la experiencia verídica dependa de la existencia de aquello de lo que es una experiencia. Si esto es así, no podemos percibir las propiedades reales de lo que es percibido puesto que podemos tener una experiencia cualitativamente idéntica pero acerca de algo que no existe en el mundo externo. Descartes concluyó (como también lo habían hecho los estoicos y los epicúreos en la Grecia antigua) que aquello de lo que somos conscientes inmediatamente en la percepción son cualidades que están en nuestro interior (las denominadas qualia, o sense data en la filosofía contemporánea) y que sólo representan aquello que 
está en el mundo exterior pero no necesariamente se corresponden con ello. Esta postura se convirtió en la concepción ortodoxa de la filosofía moderna, y tuvo como una consecuencia inevitable, la problematización de la existencia misma del "mundo exterior", con el consiguiente escepticismo derivado de esto.

2. La confusión original: ¿̨identidad o indistinguibilidad?

Ya desde la Primera Meditación el escepticismo epistemológico se ha sostenido por el siguiente planteamiento: 1) La persona A tiene la experiencia ("verídica") de que ve algún objeto, por ejemplo, una pared amarilla. 2) La persona B (o A en otro momento) tiene una experiencia no verídica (un sueño o una "alucinación total") que resulta ser "cualitativamente idéntica" con la experiencia de la A. Este escenario conduce al argumento tradicional siguiente: lo que percibimos directamente es lo mismo en los dos casos pero, en uno de ellos, la pared amarilla no existe físicamente (suponiendo que no hay nada físicamente amarillo en torno de B). De esta manera, lo que B "percibe directamente" no es físico, y, puesto que es lo mismo en los dos casos, esto quiere decir que tampoco es físico en el caso de la persona $A$, no es físico aunque la percepción sea verídica. Lo "amarillo que vemos" no es físico, sino mental, es un quale de color en ambos casos.

Según Putnam, el problema del escepticismo, nace de una confusión entre la identidad y la indistinguibilidad (Putnam, 1994a: 1112).Lo que queremos significar cuando decimos que dos experiencias son idénticas, es simplemente que son indistinguibles. ${ }^{1{ }^{1}}$ La dificultad

\footnotetext{
${ }^{11}$ Putnam describe el experimento de Parikh para mostrar esto. Se tienen cien cartas y un bote de pintura blanca. La carta 1 se pinta de blanco y se echa una gota de color rojo en la pintura del bote revolviéndola bien. Luego se pinta la carta 2 con esa pintura y se comparan los colores percibidos de las cartas 1 y 2. Ambas cartas parecen tener el mismo color, es decir, la quale entre 1 y 2, Q1/2, parece ser la
} 
consiste en que la relación de "ser indistinguible" no es transitiva, mientras que la identidad, en un sentido lógico-matemático, sí lo es. Esto quiere decir que dos qualia, por ejemplo, correspondientes a un color percibido en dos cartas diferentes, pueden ser indistinguibles sin por esto ser idénticas. Es absurdo aplicar el criterio de identidad clásico en el caso de las apariencias, para las cuales sólo puede definirse la indistinguibilidad.

Pero esto no significa que no pueda haber estados fenoménicos, entendidos como estados cerebrales perceptivos involucrados en la percepción del color y que son en parte responsables en nuestra capacidad de discriminar entre apariencias diferentes. Sin embargo, es un error identificar directamente tales estados perceptivos con las apariencias de color, ya que ambos no cumplen con las mismas propiedades. Es decir, en particular la propiedad de que apariencias diferentes sean distinguibles por parte de un sujeto, no corresponde a alguna propiedad de las excitaciones nerviosas u otros estados cerebrales perceptivos. Así, con respecto a esto, los agrupamientos de células que se excitan en un sujeto cuando un mismo tono de color particular es registrado en dos objetos diferentes pueden cambiar, aunque la apariencia del color sea la misma para el sujeto que lo percibe. Si bien puede suceder que muchas de las mismas células se exciten al registrar sucesivamente cada uno de los objetos, no todas lo hacen. Por otra

misma. Si se hace lo mismo para la carta 3 y la comparamos con la carta 2 tenemos que la quale entre 2 y 3, Q2/3 parece ser también la misma. Pero, ¿̇son idénticas Q1/2 y Q2/3? Si se continúa el procedimiento para el resto de las cartas, echando una gota de color rojo en la pintura del bote, revolviendo bien y pintando la carta siguiente con el color así obtenido, el color percibido de la carta, digamos, número 20 será notablemente distinto del color de la carta 1 . Lo cual quiere decir que la quale de color de la carta 20 no puede ser Q1/2. Esto significa que las qualia Q1/2 y Q2/3 no pueden ser idénticas ya que la identidad es una propiedad transitiva y se transmitiría hasta la carta 20. Por consiguiente las qualia son indistinguibles, pero no idénticas. 
parte, si estamos considerando la percepción de colores, entonces, algo más allá de ese agrupamiento de células excitado tiene que estar involucrado, y eso es todos aquellos procesos que estén involucrados en la adquisición de los conceptos de color requeridos.

Por esas razones la excitación de los agrupamientos de células son sólo una condición necesaria, pero no suficiente para percibir un tono de color particular. En otras palabras, los respectivos procesos de producción en los casos de las experiencias oníricas y de vigilia son diferentes, Putnam sugiere entonces un regreso al realismo natural acerca de, por ejemplo, los colores. El color que vemos cuando observamos algún objeto físico (o la apariencia de ese color bajo ciertas condiciones de observación) es una propiedad objetiva de la relación entre el organismo y el medio ambiente, en vez de considerarlo una propiedad de nuestras mentes.

Volviendo al caso de la comparación cartesiana entre la experiencia onírica y la de vigilia. En el primer caso, el de la vigilia, somos conscientes de una apariencia de color objetiva, "tal que nuestro estado perceptivo es un estado relacional, un modo en que interactuamos con una propiedad del entorno" (Putnam, 1997: 14).

Mientras que en el caso de la experiencia onírica de color, sólo nos parece ser conscientes de una apariencia de color objetiva. Únicamente en el segundo caso podemos hablar de un estado perceptivo interior al organismo. Las dos experiencias, la interna y la externa pueden ser indistinguibles pero no son idénticas. Pero dos estados perceptivos diferentes pueden causar experiencias indistinguibles. Dice Putnam, "Uno puede, como decimos en el lenguaje ordinario, 'tener la misma experiencia' y no estar en el mismo estado perceptivo. Y esto es lo que ha parecido absurdo a tantos filósofos desde Descartes hasta el día de hoy" (Putnam, 1997: 15).

El hecho de que puede haber estados perceptivos indistinguibles que no son idénticos, pero que a su vez originen experiencias indistinguibles, tiene consecuencias que refutan el viejo argumento escéptico 
de que no podemos ser conscientes de propiedades externas de las cosas. La imagen tradicional de la percepción que se somete a crítica, es aquella que muestra a la percepción no como una conciencia de las cosas y sus propiedades en un medio, sino como una conciencia de imágenes dentro de nuestras cabezas. La percepción se transforma así, no en un medio de acceso al mundo sino en una interfaz entre nosotros y el mundo, a partir de la cual debemos hacer "inferencias" problemáticas con respecto a lo que hay afuera.

Una consecuencia más de la imagen interfaz es que, si bien, en algún sentido podemos afirmar que "percibimos directamente" a los objetos observables de nuestro mundo cotidiano, hay algo más esencial del objeto observado que está "más allá" de su mera apariencia. Y respecto a los objetos científicos - tales como los gérmenes, las moléculas, o las partículas elementales- se tiende a pensar que estos no son percibidos y deben ser, en consecuencia, construcciones lógicas (como en el positivismo lógico) o inferidos a partir de aquello que "percibimos directamente", ignorando la observación con ayuda de instrumentos como una forma de percepción. La idea de que hay un abismo epistemológico entre la percepción de, por ejemplo, mesas y sillas, y la percepción de un virus mediante un microscopio electrónico surge cuando restamos importancia a las maneras como, en la práctica, vemos una actividad como continuación natural de otra.

\section{Conclusión}

Un problema de la concepción interfaz, tanto en su versión tradicional como en su versión materialista contemporánea, es que los sense data, qualia, o las representaciones contemporáneas, juegan un papel análogo al de las impresiones de los clásicos. Pero en la ciencia cognitiva de hoy se identifica a la mente como un órgano: el cerebro, y las representaciones son los outputs de los procesos perceptivos, que a su vez son los inputs de los procesos cognitivos, los insumos a partir 
de los cuales la computadora cerebral hace inferencias. El problema surge al pretender identificar a estos insumos con los qualia y toda su riqueza cualitativa. Según Putnam este reduccionismo bajo la forma de una pretendida naturalización con base científica es muy discutible. Otro problema adicional de esta concepción es que las representaciones están ligadas sólo causalmente a los objetos del medio ambiente del organismo sin que haya ningún vínculo cognitivo (o epistémico, de la misma forma en que las impresiones sólo estaban ligadas causalmente con los objetos externos).

Esta imagen interfaz, tanto en su versión clásica como en su versión contemporánea, ha sido nefasta para la metafísica y para la epistemología. Pues supone que tiene que haber interfaces entre nuestras capacidades cognitivas y el mundo exterior o, en otros términos, supone que nuestros poderes cognitivos no pueden extenderse hasta alcanzar los objetos mismos.

El realista natural, en el sentido de James, sostiene que la percepción exitosa consiste en ver, o escuchar, las cosas que están allí afuera, y no en una mera afección de la subjetividad causada por esas cosas. Putnam, como James, señala que esta forma de ver la experiencia sensorial como experiencia intermediaria entre nosotros y el mundo, ha sido el origen de muchos de los problemas filosóficos acerca de la percepción y la experiencia, pues nos ha impedido verla como nuestro contacto cognitivo genuino con el mundo.

El realista natural señala que, cuando la percepción es verídica, el contenido de nuestras creencias perceptivas son los hechos del mundo, y no meras representaciones subjetivas del mismo: mediante la percepción, la mente está en contacto directo con el mundo. La alternativa del realismo natural supone el reto de construir una nueva semántica que prescinda de la visión de la actividad de "representación" como una interfaz entre nosotros y aquello sobre lo que pensamos, sin abandonar totalmente la idea de la representación como parte de los procesos cognitivos. 
La filosofía última de Putnam es terapéutica, en el sentido de que busca la disolución de lo que considera son errores filosóficos, por muy arraigados que estos estén en la tradición; a la vez que desarrolla una propuesta que resulta novedosa, si bien surge de la recuperación de tesis que han caído en desuso. El resultado de este largo viaje de indagación filosófica resulta ser sorprendente: la vuelta a la ingenuidad del sentido común.

\section{Bibliografía}

Aristóteles, 1999, Acerca del alma, T. Calvo Martínez (trad.), Gredos, Madrid. Austin, John, 1962, Sense and Sensibilia, Oxford University Press, Oxford.

, 1981, Sentido y percepción, A. García Suárez y L. Valdés Villanueva (trads.), Técnos, Madrid.

Dancy, Jonathan, 1985, An Introduction to Contemporary Epistemology, Blackwell, Oxford.

, 1993, Introducción a la epistemología contemporánea, J.L Prades Selma (trad.), Tecnos, Madrid.

Jackson, Frank, 1993, perception. A Representative Theory, Cambridge University Press, Cambridge.

McDowell, John, 1994, Mind and World, Harvard University Press, Cambridge. , 2003, Mente y mundo, M. A. Quintana (trad.), Sígueme, Salamanca.

Putnam, Hilary, 1981, Reason, Truth and History, Cambridge University Press, Cambridge. , 1987, The Many Faces of Realism, Open Court Pub., La Salle.

, 1988, Razón, verdad e historia, J. M. Esteban (trad.), Técnos, Madrid. , 1988a, Representation and Reality, MIT Press, Cambridge.

, 1994, Las mil caras del realismo, M. Vázquez Campos y A. Liz Gutiérrez (trads.), Paidós, Barcelona.

, 1994a, "The Dewey Lectures 1994. Sense, nonsense and the Senses: An

Inquiry into the Powers of the Human Mind", en The Journal of Philosophy, vol. XCI, núm. 9, sep., Nueva York, pp. 445-517.

, 1994b, The Return of Aristotle en Words and Life, Harvard University Press, Cambridge. 
1995, Representación y realidad. Un balance crítico del funcionalismo, G.

Ventureira (trad.), Gedisa, Barcelona.

, 1997, "El retorno de Aristóteles", en La herencia del pragmatismo, M. Liz y

M. Vázquez (trads.), Paidós, Barcelona.

, 1997a, "Modificando la (concepción de la) mente de Aristóteles", en La herencia del pragmatismo, op. cit.

, 2000, Sentido, sinsentido y los sentidos, N. Goethe (trad.), Paidós, Barcelona.

y Martha Nussbaum, 1994, Changing Aristotle Mind en Words and Life, Harvard University Press, Cambridge.

Reid, Thomas, 1764, An inquiry into the Human Mind on the Principles of Common Sense, The University of Chicago Press, Chicago y Londres, en http:// www.earlymoderntexts.com/rein.html

1785, Essays on the Intelectual Powers of Man, The MIT Press, Cambridge y Londres, 1969, en http://www.earlymoderntexts.com/reip.html

, 1998, Ensayos sobre las capacidades intelectuales del hombre, en La filosofía del sentido común. Breve antología de textos de Thomas Reid, J. Hernández Prado (trad.), UAM Azcapotzalco, México.

, 1998, Una investigación de la mente humana bajo los principios del sentido común, en La filosofía del sentido común. Breve antología de textos de Thomas Reid, op cit. 